\title{
A MULTI-WIDEBAND STACKED PATCH ANTENNA WITH PARASITIC RESONATORS AND SWITCHED SLOTS
}

\author{
Elsayed Esam M. Khaled', and Ayman A. R. Saad ${ }^{2}$ \\ ${ }^{1}$ Elec. Eng. Dept., Assiut University, Assiut, Egypt, \\ esamk54_2000@hotmail.com, \\ ${ }^{2}$ Kosseir Radio, Telecom Egypt, kosseir,Egypt, demas@yahoo.com
}

(Received April 11, 2009 Accepted May 25, 2009).

\begin{abstract}
A compact stacked microstrip patch antenna is proposed based on slot matching concept. Double layers of patches with parasitic resonator elements and substrates are manipulated in a stacked configuration. Slots and switches are integrated to each patch to enhance the antenna applicability for multi-wideband applications. The dimensions of the patches, parasitic elements, slots, and states of the switches and their positions are designed such that the antenna gives different number of resonant frequencies. The proposed antenna is capable to achieve a return loss less than $-9.54 \mathrm{~dB}$ and voltage standing wave ratio $\leq 2$ in almost nine frequency bands within a frequency range of $2-5 \mathrm{GHz}$.
\end{abstract}

\section{INTRODUCTION}

The most two serious problems for a design of the microstrip patch antenna are its low gain and narrow bandwidth. The compact antenna configuration further deteriorates these two parameters. As the antenna gets smaller in size, its operating bandwidth and efficiency decrease. Also a small patch antenna provides lower gain than larger antenna [1]. Therefore, the size reduction together with gain and bandwidth enhancement is becoming major design considerations for most practical applications of this type of antennas. Moreover the multi-band applications of smaller patch antennas are overwhelming importance of the mobile communications market $[2,3]$. Multi-wideband antennas design can be achieved using a stacked configuration that increase number of resonant frequencies and enhance the gain and bandwidths [4-10].

A stacked microstrip antenna has two or more patches on different dielectric substrates that are stacked on each other. This construction increases the overall height of the antenna but the surface area in the planar direction remains as that of the singlepatch antenna of the same operation considerations. Thus the stacked antenna is suitable for applications which use array of antenna elements. Several designs have been developed for multi-band stacked patch antennas such as stacked shorted patch antenna that achieved multi-resonances. Such design suffers from narrow bandwidths and low gain [6-8].

In this paper, a design of a multi-wideband compact microstrip patch antenna is presented in stacked configuration. The operating frequency range of the proposed antenna is 2-5 GHz. This frequency range is used in different applications such as wireless local area network (WLAN), mobile worldwide interoperability for microwave access (Mobile WiMAX), and wide code division multiple access (WCDMA). Here we will investigate the effects of geometry change in the resonance 
frequencies to design an antenna that can be used for multi applications. The simulation of the antenna is carried out using the 3-D full wave method of moments (MoM) software package (IE3D) coded by Zeland software [11]. The description of the antenna design is outlined in section 2. Simulation of the antenna and discussion are presented in section 3. Conclusions are given in section 4 .

\section{ANTENNA DESIGN}

The geometry of the proposed antenna is shown in Figure 1. It consists of a design similar to that presented by Alayesh [10]. The elements and dimensions of the proposed antenna are taken from a design of a single-layer antenna presented by Khaled et al [3]. The construction mainly consists of a conventional patch antenna of a central frequency of $2.4 \mathrm{GHz}$. The dimensions of the ground plane and the patch are $50.95 \times 59.00 \mathrm{~mm}^{2}$ and $41.35 \times 49.41 \mathrm{~mm}^{2}$ respectively. The thickness of the dielectric substrate between the patch and the ground plane is $1.6 \mathrm{~mm}$ and made from RT/ Duroid 5880 with relative permittivity $\varepsilon_{r 1}=2.2$. The material of the substrate is chosen such that it gives better efficiency and wider bandwidth. A second layer consists of a patch and a substrate from fused quartz material of $\varepsilon_{r 2}=3.8$ and thickness of $1.0 \mathrm{~mm}$ is placed on the top of first layer to obtain more resonance frequencies and wider bandwidths [10]. The two patches are of the same geometry. The top patch (parasitic patch) is surrounded by slots named by 8,9 , and 10 as shown in the figure. Their dimensions are given in Table 1. Also the patch is partially enclosed with parasitic resonator elements of two parallel inverted L-shaped arms spaced with $1.3 \mathrm{~mm}$ slit. Switches $\mathrm{sw}_{3}, \mathrm{sw}_{4}$ are integrated to slots 6 and 7 respectively to switch between the resonant frequencies in order to make the antenna usable for different applications [3]. The bottom patch (fed patch) has slots named 1, 2, 3, 4, and 5 with positions and dimensions similar to the corresponding slots $8,9,10,6$, and 7 respectively. Switches $\mathrm{sw}_{1}, \mathrm{sw}_{2}$ similar to the corresponding $\mathrm{sw}_{3}, \mathrm{sw}_{4}$ are integrated to slots 4 and 5. Parasitic resonator elements similar to those in the top patch are constructed with the bottom patch. The antenna is fed by a coaxial feeding probe of radius $3.0 \mathrm{~mm}$ constructed through the patch of the bottom layer. As stated previously the antenna design presented here is similar to that design presented by Alayesh [10] except that we added the parasitic resonator elements in both layers. These two parasitic resonators are both shorted with the ground plane through a ground shorted strip. This modification increases number of the resonant frequencies and enhances bandwidths and gain of the antenna as illustrated in the next section. The specification of the proposed antenna is presented in Table 1. The positions and dimensions of the parasitic elements, slots and switches are optimized to yield the required number of resonance frequencies, wide bandwidths and high gain.

\section{SIMULATION OF THE ANTENNA AND DISCUSSION}

The simulation of the proposed antenna is carried out using IE3D Zeland software [11]. For an initial design the optimum feeding point is located at $\left(X_{f}, Y_{f}\right)=(-6.35,0)[3]$. The simulation of the first layer alone (a patch antenna with the parasitic element and 
slots) showed more resonant frequencies with return losses $(\mathrm{RL}) \leq-9.54 \mathrm{~dB}$ than that of the conventional patch antenna in the range of $2-5 \mathrm{GHz}[3,9,10]$.

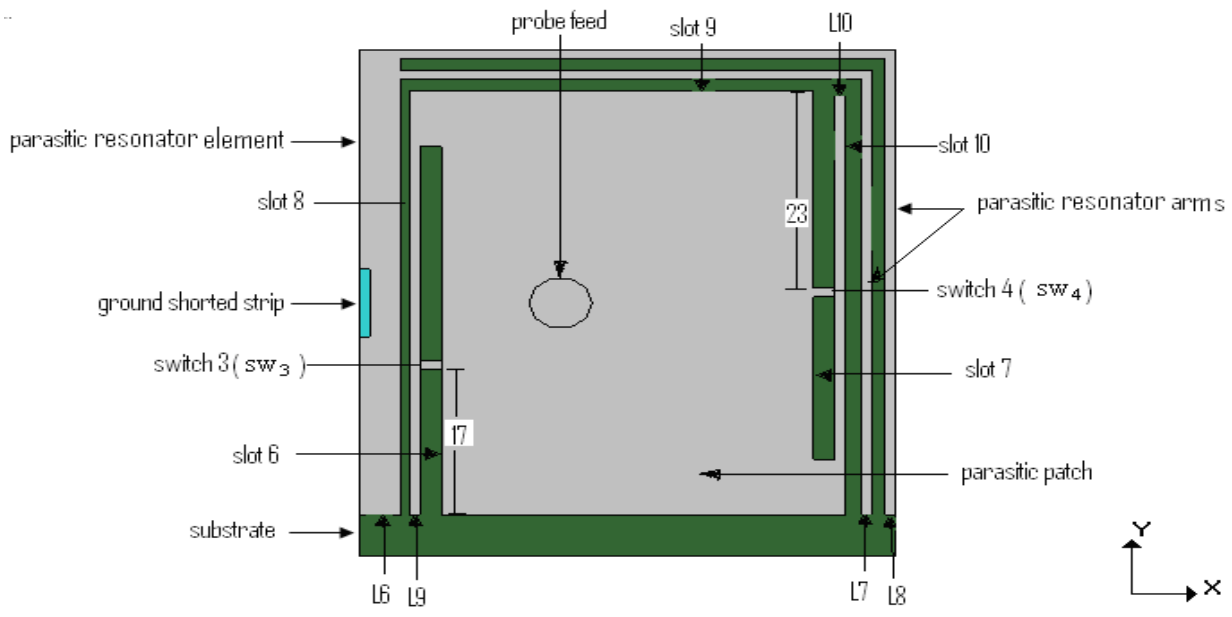

(a)

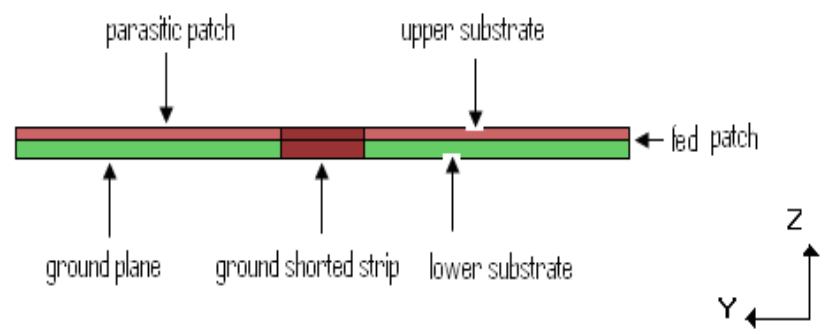

(b)

Figure 1. The geometry and parameters of the proposed antenna.

(a) top-view, (b) side-view.

Adding a parasitic resonator element surrounding the patch antenna significantly reduces the value of its resonance frequency. The reasons for that are first the radiator surface gets electrically larger when the parasitic element is introduced. Second the separation between the patch and the parasitic element introduces an electromagnetic coupling between the two metal sheets which is a capacitive loading. The slot between the patch and the parasitic resonator element acts as an electrical delay of the RF-signal traveling from the patch to the parasitic resonator element. This delay implies that the antenna is electrically larger than that of the patch itself [9].

Since the resonance frequency can be determined by the mean current path, therefore any disturbance of the path can affect strongly the resonant frequency. Number of the resonant frequencies can be increased by loading two slots on the patch [3]. The resonance frequencies can be tuned by varying the lengths of the slots. Increasing the path length of the surface current reduces the values of the resonance frequencies. The simulation of the conventional patch antenna of one layer with the parasitic resonator element and slots of the bottom layer alone illustrates that slot 1 affects the low frequency band, slot 3 affects the high frequency band, and slot 2 
affects both high and low frequency bands. The slit between the parasitic resonator arms controls the low frequency band [3].

Table 1. Specifications of the proposed antenna in $\mathrm{mm}$.

\begin{tabular}{|c|c|}
\hline Elements & Dimensions (mm) \\
\hline Ground plane & $50.95 \times 59.00(\mathrm{LxW}) . \mathrm{L}=$ length, W=width \\
\hline $\begin{array}{l}\text { bottom (fed) and top (parasitic) } \\
\text { patchs }\end{array}$ & $41.35 \times 49.41(\mathrm{LxW})$ \\
\hline Patchs thicknesses & 0.07 \\
\hline Height of the bottom substrate & 1.6 \\
\hline $\begin{array}{l}\text { Relative permittivity of the bottom } \\
\text { substrate }\end{array}$ & $\varepsilon_{r 1}=2.2$ \\
\hline Height of the top substrate & 1.0 \\
\hline $\begin{array}{l}\text { Relative permittivity of the top } \\
\text { substrate }\end{array}$ & $\varepsilon_{r 2}=3.8$ \\
\hline $\begin{array}{l}\text { Feeding point location of the } \\
\text { bottom patch }\end{array}$ & $\begin{array}{l}\left(\mathrm{x}_{f}, \mathrm{y}_{f}\right)=(-6.35,0.0) \text {, the center of the } \\
\text { antenna is at }(0,0) .\end{array}$ \\
\hline Probe feeding radius & 3.0 \\
\hline $\begin{array}{l}\text { Widths of the top parasitic } \\
\text { resonator element }\end{array}$ & $\mathrm{L} 6=4, \mathrm{~L} 7=\mathrm{L} 8=1$ \\
\hline Ground shorted strip & 1x8 (LxW). \\
\hline $\begin{array}{l}\text { The slit between the parasitic } \\
\text { element arms }\end{array}$ & 1.3 \\
\hline $\begin{array}{l}\text { Widths of the slots around the } \\
\text { bottom patch }\end{array}$ & slot $1=0.8$, slot $2=1.495$, slot $3=1.5$ \\
\hline $\begin{array}{l}\text { Widths of the slots around the top } \\
\text { patch }\end{array}$ & slot $8=0.8$, slot $9=1.495$, slot $10=1.5$ \\
\hline $\begin{array}{l}\text { Dimensions and positions of slot } 6 \\
\& \text { slot } 7\end{array}$ & $2 \times 43(\mathrm{LxW})$ at distances $\mathrm{L} 9=\mathrm{L} 10=1$. \\
\hline $\begin{array}{l}\text { Dimensions and positions of slot } 4 \\
\& \text { slot } 5\end{array}$ & The same as slot 6 and slot 7 respectively. \\
\hline $\begin{array}{l}\text { Positions of switches } \mathrm{sw}_{3} \& \mathrm{sw}_{4} \text { in } \\
\text { the top patch }\end{array}$ & $\begin{array}{l}2 \times 1(\mathrm{LxW}) \text { at } 17 \text { and } 23 \mathrm{~mm} \text { from the } \\
\text { open edge of the slots } 6 \text { and } 7 \\
\text { respectively. }\end{array}$ \\
\hline $\begin{array}{l}\text { Positions of switches } \mathrm{sw}_{1} \& \mathrm{sw}_{2} \text { in } \\
\text { the bottom patch }\end{array}$ & $\begin{array}{l}\text { The same as switches } \mathrm{sw}_{3} \text { and } \mathrm{sw}_{4} \\
\text { respectively. }\end{array}$ \\
\hline
\end{tabular}

Using the above results, we can choose appropriate slots lengths (in the $x$ direction) and positions to get a suitable resonant frequencies and bandwidths over the operating frequency range depending on the application that uses the antenna. In the present design the positions of these slots are optimally chosen by the trial and error to give more resonant frequencies. The lengths of the slots $6,7,4$ and 5 are found to be $2.0 \mathrm{~mm}$. Splitting the slots create unequal lengths for two separate current paths. These current paths correspond to hybrid operating modes which result in wideband characteristics. The generated resonances are of different modes. To change the slots 
lengths and hence the current bathes to tune the resonant frequencies switches are integrated into the slots where the current paths become shorter and hence the resonance frequencies get higher values. These resonant frequencies depend on the states of the switches [3]. For the stacked configuration design the positions of switches $\mathrm{sw}_{1}$ and $\mathrm{sw}_{2}$ are at $17 \mathrm{~mm}$ and $23 \mathrm{~mm}$ from the open edge of slots 4 , and 5 respectively. Also the switches $\mathrm{sw}_{3}$ and $\mathrm{sw}_{4}$ are at similar positions along slot 6 and slot 7 respectively. The RL of the proposed stacked antenna with switches $\mathrm{sw}_{1}$ and $\mathrm{sw}_{2}$ are on is shown in Figure 2 for different states of $\mathrm{sw}_{3}$ and $\mathrm{sw}_{4}$. The results show that the number of resonance frequencies with RL less than $-9.54 \mathrm{~dB}$ in the operated frequency range depends on the states of the switches $\mathrm{sw}_{3}$ and $\mathrm{sw}_{4}$.

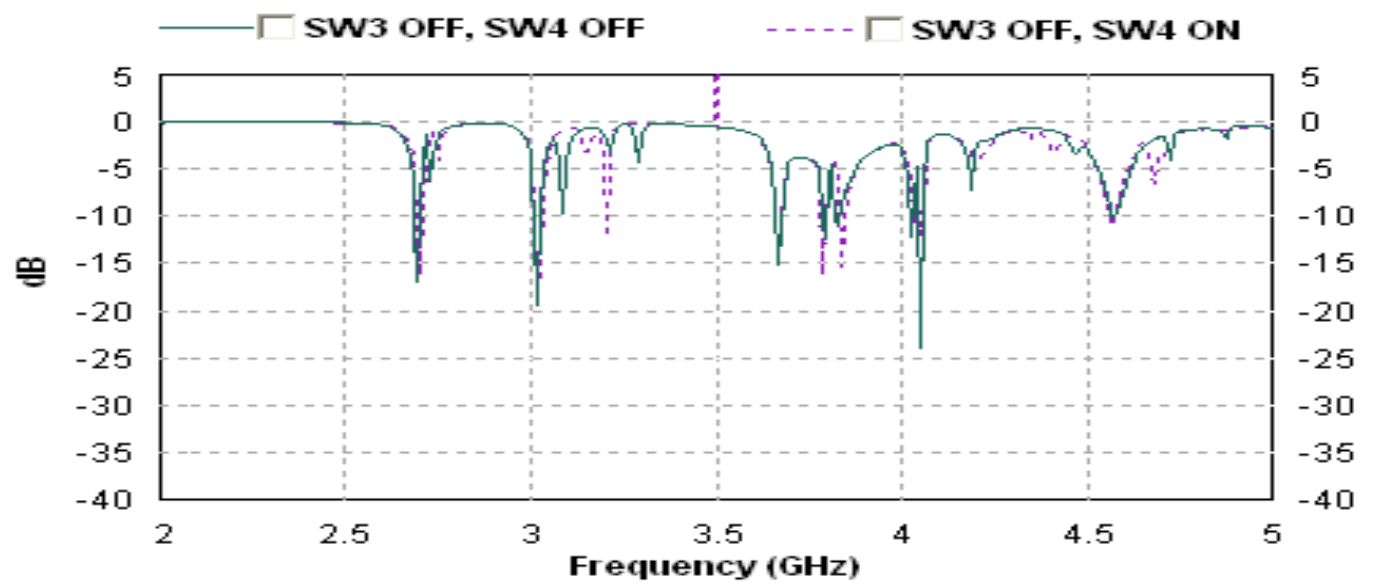

(a)

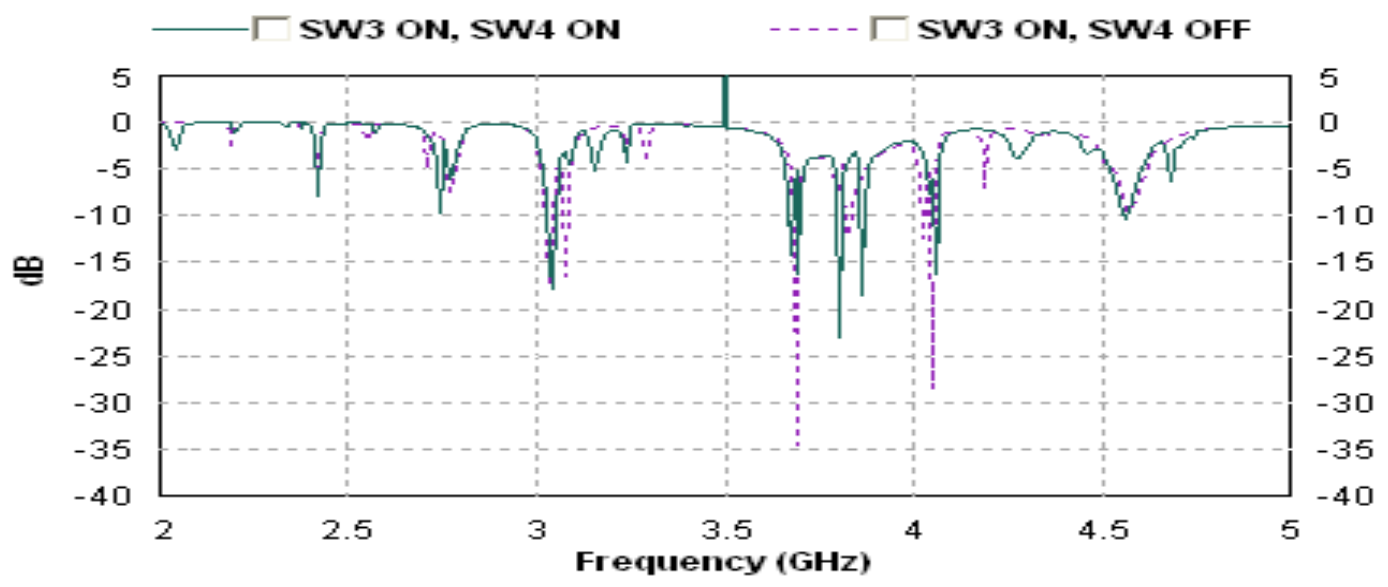

(b)

Figure 2. Return loss as a function of frequency for the proposed antenna with $\mathrm{sw}_{1}$ and $\mathrm{Sw}_{2}$ are on,

(a) the state of $\mathrm{sw}_{3}$ and $\mathrm{sw}_{4}$ are off, and the state of $\mathrm{sw}_{3}$ is off and $\mathrm{sw}_{4}$ is on,

(b) the state of $\mathrm{sw}_{3}$ and $\mathrm{sw}_{4}$ are on, and the state of $\mathrm{sw}_{3}$ is on and $\mathrm{sw}_{4}$ is off. 
The impedance bandwidths of the nine resonance frequencies are calculated as a full-width at half-maximum (FWHM) at RL $\leq-9.45 \mathrm{~dB}$ with states of the switches $\mathrm{sw}_{1}$ and $\mathrm{sw}_{2}$ are on, and $\mathrm{sw}_{3}$ and $\mathrm{sw}_{4}$ are off. The calculated results are given in Table 2. The resonant frequencies and impedance bandwidths for stacked patch antenna design presented in Ref. [10] which has no parasitic elements resonators are given in Table 3. The results in Tables 2 and 3 illustrate that the present design gives more resonance frequencies and some wider bandwidths.

Table 2. Calculated resonant frequencies and impedance bandwidths of the proposed antenna.

\begin{tabular}{|c|c|}
\hline Resonant frequency $(\mathrm{GHz})$ & Impedance Bandwidth $(\mathrm{MHz})$ \\
\hline 2.6975 & 17.7 \\
\hline 3.0200 & 22.1 \\
\hline 3.0875 & 2.9 \\
\hline 3.6650 & 22.1 \\
\hline 3.7925 & 14.7 \\
\hline 3.8300 & 19.1 \\
\hline 4.0250 & 13.2 \\
\hline 4.0475 & 16.2 \\
\hline 4.5725 & 26.5 \\
\hline
\end{tabular}

Table 3. Resonant frequencies and impedance bandwidths of the design presented in Ref. [10].

\begin{tabular}{|c|c|}
\hline Resonant frequency $(\mathrm{GHz})$ & Impedance Bandwidth $(\mathrm{MHz})$ \\
\hline 3.2750 & 13.3 \\
\hline 3.4820 & 13.3 \\
\hline 3.7340 & 108.3 \\
\hline 4.0730 & 13.3 \\
\hline 4.5200 & 50.0 \\
\hline 4.8860 & 91.7 \\
\hline
\end{tabular}

The average surface current distributions at different resonant frequencies of the proposed antenna are simulated and shown in Figure 3. The simulation is manipulated, as an example, for the antenna with states of the switches $\mathrm{sw}_{1}$ and $\mathrm{sw}_{2}$ are on, and $\mathrm{sw}_{3}$ and $\mathrm{sw}_{4}$ are off. It is observed that the current is concentrated around the slots and the parasitic resonator elements. 


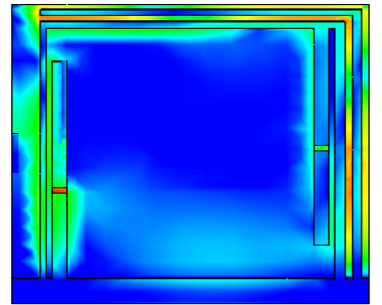

(a)

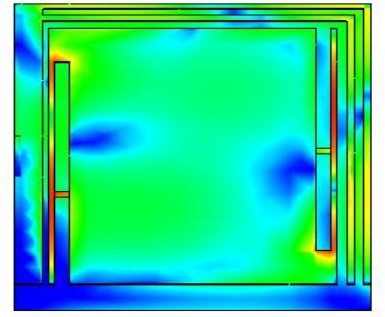

(c)

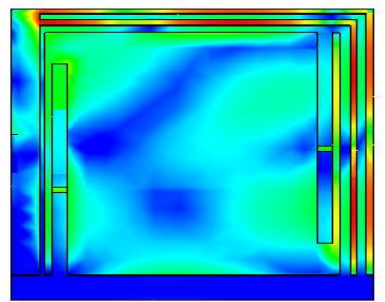

(e)

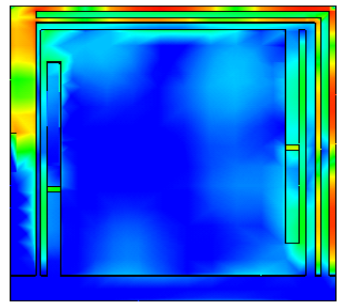

(g)

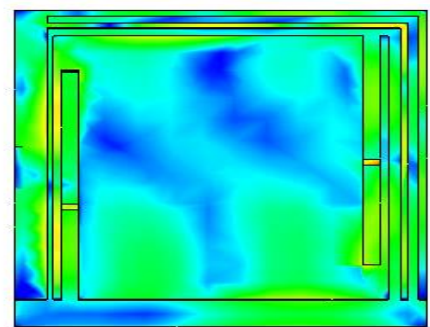

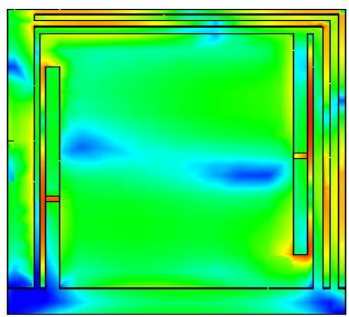

(b)

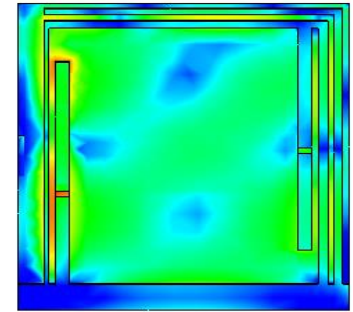

(d)

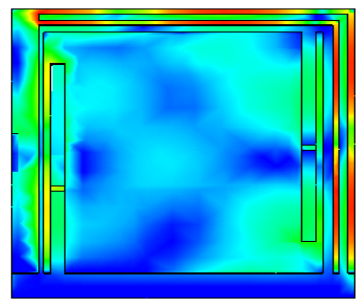

(f)

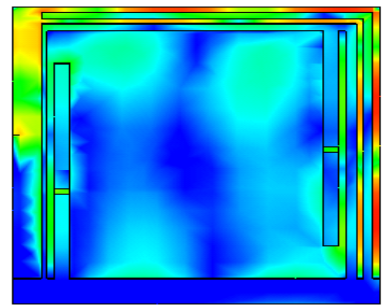

(h)

(i)

Figure 3. Simulated average surface current distributions at different resonance frequencies of the proposed stacked antenna with the states of switches $\mathrm{sw}_{1}$ and $\mathrm{sw}_{2}$ are on, and $\mathrm{sw}_{3}$ and $\mathrm{sw}_{4}$ are off $(\mathrm{a}) \mathrm{f}_{\mathrm{r}}=2.6975 \mathrm{GHz},(\mathrm{b}) \mathrm{f}_{\mathrm{r}}=3.0200 \mathrm{GHz},(\mathrm{c}) \mathrm{f}_{\mathrm{r}}=3.0875 \mathrm{GHz}$, (d) $\mathrm{f}_{\mathrm{r}}=3.6650 \mathrm{GHz},(\mathrm{e}) \mathrm{f}_{\mathrm{r}}=3.7925 \mathrm{GHz}$, (f) $\mathrm{f}_{\mathrm{r}}=3.8300 \mathrm{GHz},(\mathrm{g}) \mathrm{f}_{\mathrm{r}}=4.0250 \mathrm{GHz}$, (h) $\mathrm{f}_{\mathrm{r}}=4.0475 \mathrm{GHz},(\mathrm{i}) \mathrm{f}_{\mathrm{r}}=4.5725 \mathrm{GHz}$. 
The variation of the voltage standing wave ratio (VSWR) with the frequency for the proposed antenna is shown in Figure 4. The simulation is given for $\mathrm{sw}_{1}$ and $\mathrm{sw}_{2}$ are on and different states of the switches $\mathrm{sw}_{3}$ and $\mathrm{sw}_{4}$. The results show that the VSWR is $\leq 2$ at the resonant frequency bands corresponding to a $\mathrm{RL} \leq-9.54 \mathrm{~dB}$ which are acceptable for practical applications. Figure 2 and 4(b) show that at the resonant frequency of $3.5 \mathrm{GHz}$ the proposed antenna has almost perfect input impedance matching at certain states of the switches.

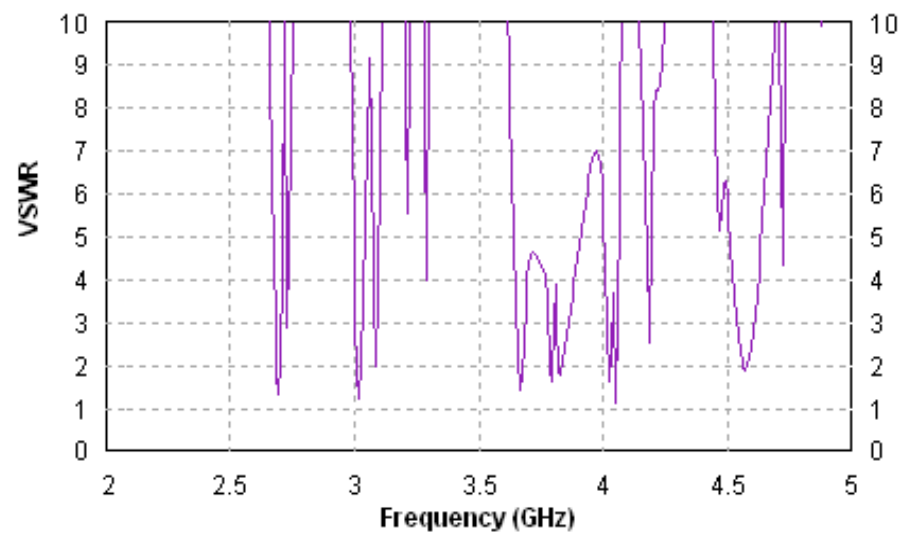

(a)

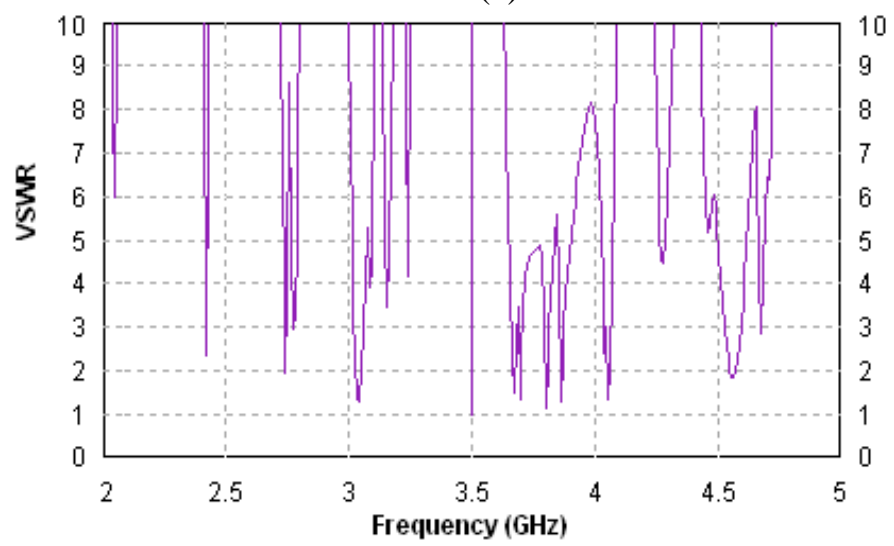

(b)

Figure 4. VSWR of the proposed antenna as a function of frequency, (a) states of the switches $\mathrm{sw}_{1}$ and $\mathrm{sw}_{2}$ are on, and $\mathrm{sw}_{3}$ and $\mathrm{sw}_{4}$ are off, (b) switches $\mathrm{sw}_{1}$ to $\mathrm{sw}_{4}$ are on.

Figure 5 shows the simulated radiation patterns of the electric field $|\mathrm{E}|$ in the $\varphi=0^{\circ}$, and $\varphi=90^{\circ}$ planes at the resonant frequencies with states of $\mathrm{sw}_{1}$ and $\mathrm{sw}_{2}$ are on, and states of $\mathrm{sw}_{3}$ and $\mathrm{sw}_{4}$ are off. The results show that at some resonance frequencies wide variations of the radiation pattern with small radiated power in the back lobes are obtained. The back lobes in the radiation pattern are small due to the ground plane of the antenna. The advantages of reducing radiation from back lobes is that minimizing the electromagnetic power radiated back to the heads of the headsets users. The results illustrate that the best operated frequencies are $2.6975 \mathrm{GHz}, 3.02 \mathrm{GHz}, 3.0875 \mathrm{GHz}$ and $3.665 \mathrm{GHz}$. Adding parasitic elements with ground shorted strip parallel to the 
radiating edges of the patches in the present design minimizes the surface wave radiation. Such radiations are existed if the antenna has no parasitic elements [10] which cause distortion to the main beam pattern and increasing the side and back beam radiations.

The directivity of the proposed antenna is simulated and shown in Figures 6. It depicts that the peak of the directivity at the resonant frequencies $2.6975,3.0200$, $3.0875,3.6650,3.7925,3.8300,4.0250,4.0275$, and $4.5725 \mathrm{GHz}$ are approximately 7.1, 5.6, 5.7, 5.0, 5.9, 6.8, 6.0, 5.8, and $6.5 \mathrm{dBi}$ respectively. The behaviors of the antenna efficiency and radiating efficiencies are presented in Figure 7. The computed results in Figures 6 and 7 illustrate that the proposed antenna has a high directivity and radiation efficiency. The radiation efficiency is higher than $90 \%$ over the operated frequency range, since there are no high dielectric losses and no surface wave losses such as those exists in the conventional patch antenna. All the above results show that the proposed antenna provides more enhancements of multi-wideband operation than those of a single layer patch antenna of the same design.

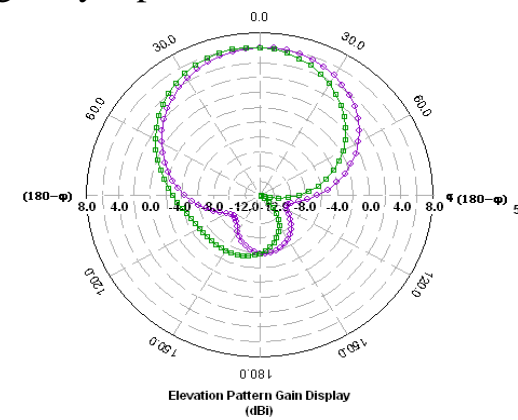

a)

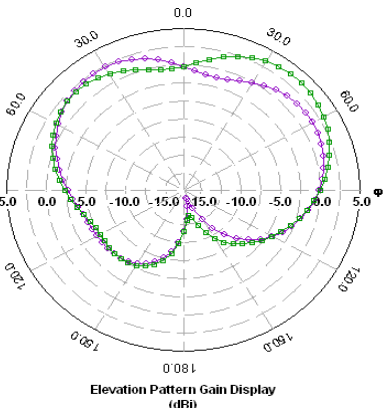

(b)

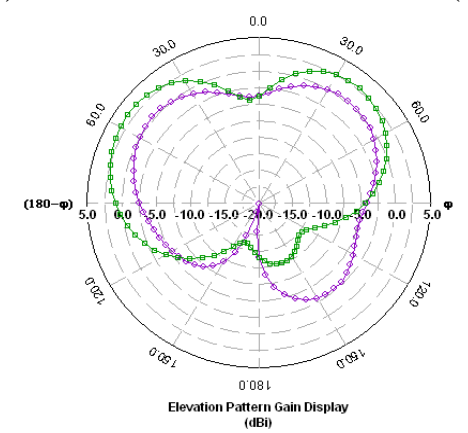

(c)

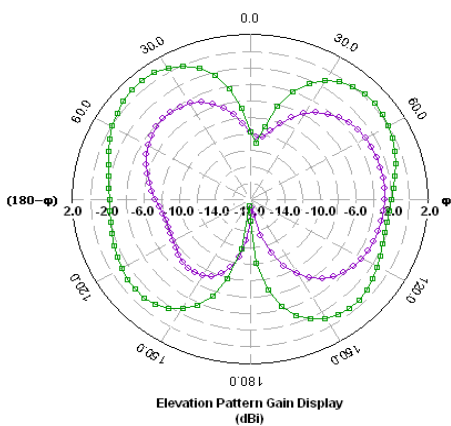

(d)

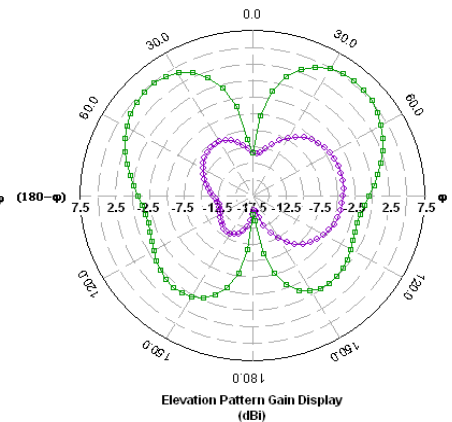

(e) 


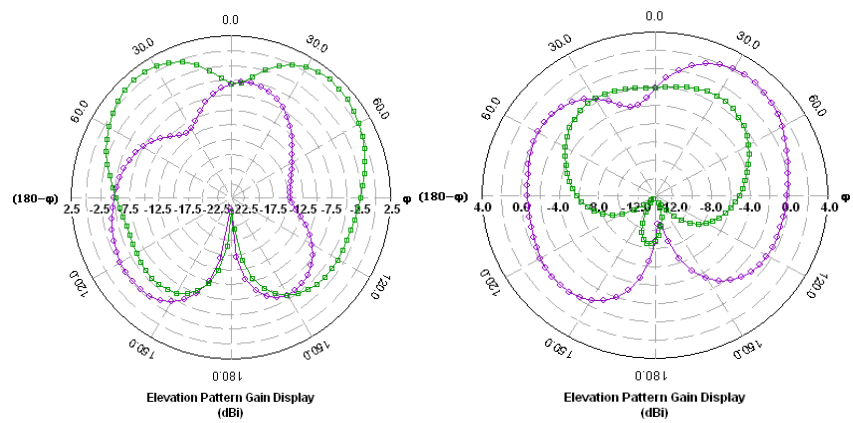

(f)

(g)

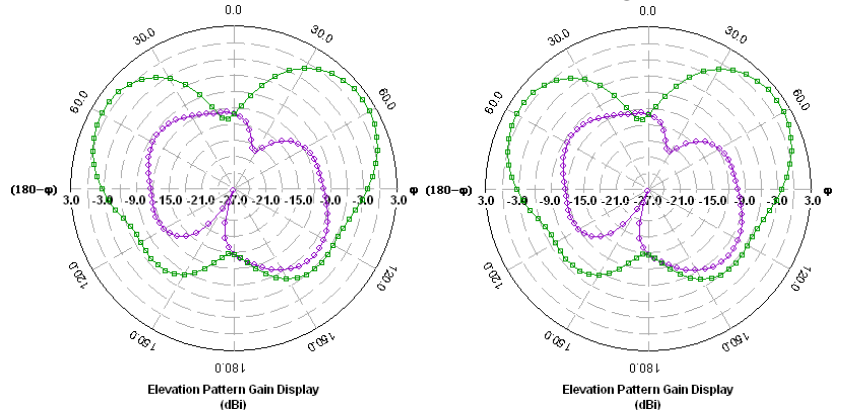

(h)

(i)

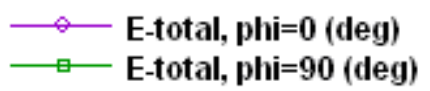

Figure 5. Radiation pattern of $E$-fields in the $\varphi=0^{\circ}$ and $\varphi=90^{\circ}$ planes at different resonant frequencies with the same states of the switch as those in Figure4(a),

(a) $\mathrm{f}_{\mathrm{r}}=2.6975 \mathrm{GHz},(\mathrm{b}) \mathrm{f}_{\mathrm{r}}=3.0200 \mathrm{GHz},(\mathrm{c}) \mathrm{f}_{\mathrm{r}}=3.0875 \mathrm{GHz},(\mathrm{d}) \mathrm{f}_{\mathrm{r}}=3.6650 \mathrm{GHz}$, (e) $\mathrm{f}_{\mathrm{r}}=3.7925 \mathrm{GHz}$, (f) $\mathrm{f}_{\mathrm{r}}=3.8300 \mathrm{GHz},(\mathrm{g}) f_{i}=4.0250 \mathrm{GHz},(\mathrm{h}) f_{i}=4.0475 \mathrm{GHz}$, (i) $f_{i}=4.5725 \mathrm{GHz}$.

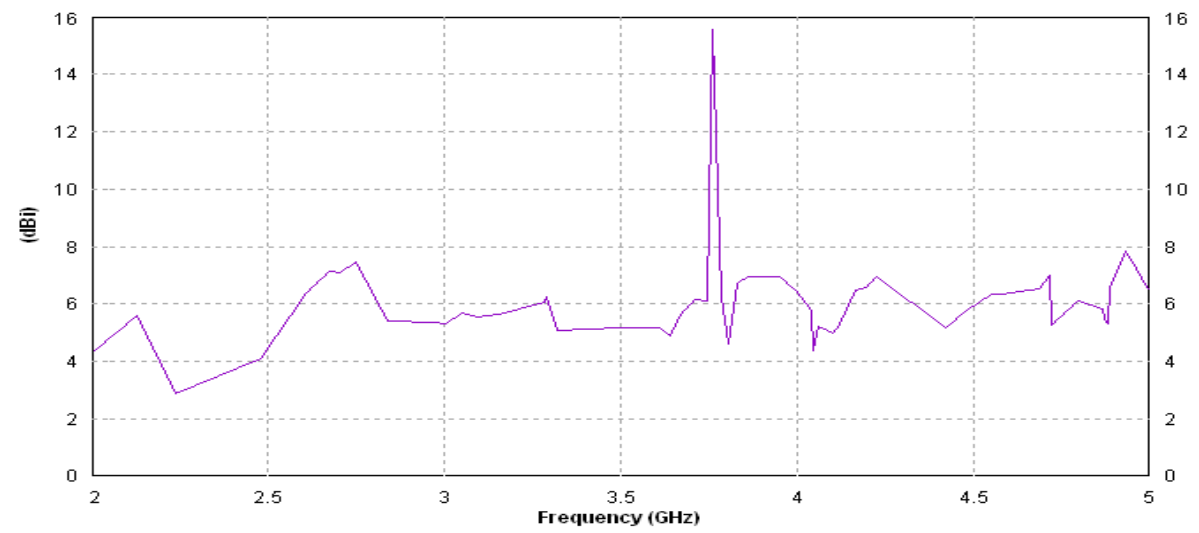

Figure 6. Behaviors of the directivity as a function of frequency of the proposed antenna with states of the switches $\mathrm{sw}_{1}$ and $\mathrm{sw}_{2}$ are on, and $\mathrm{sw}_{3}$ and $\mathrm{sw}_{4}$ are off. 


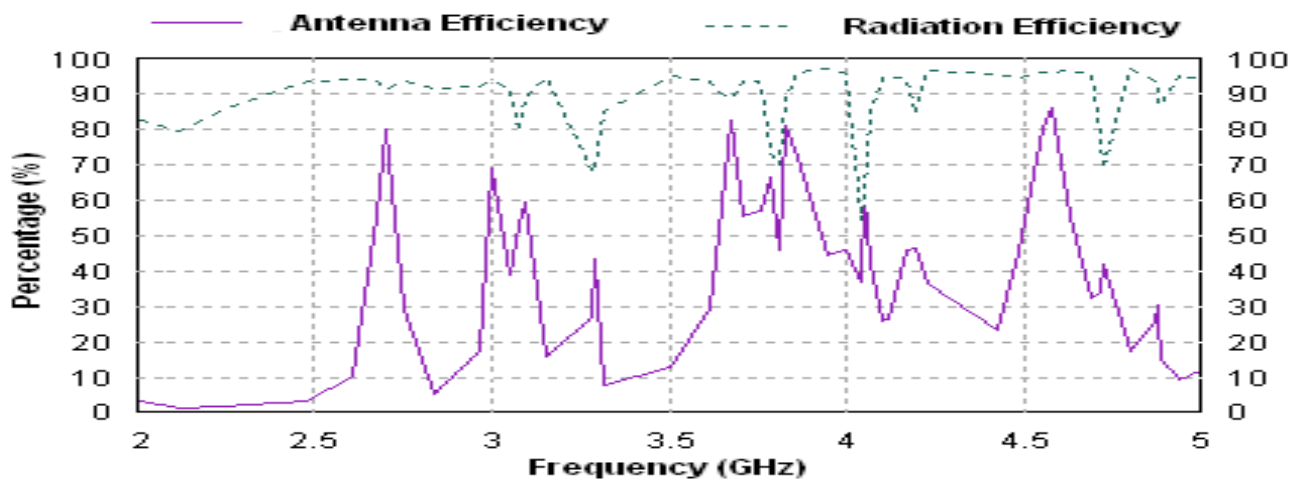

Figure 7. Behaviors of the antenna and radiation efficiencies of the proposed antenna as a function of frequency.

\section{CONCLUSIONS}

A double layered stacked microstrip patch antenna with a single probe, feeding the lower patch, operated in the frequency range of $2-5 \mathrm{GHz}$ is presented. Parasitic resonator elements and slots with two switches are added to each patch in order to enhance and control the number of the resonant frequencies and bandwidths. The behaviors of the return loss in a frequency range $2-5 \mathrm{GHz}$ is illustrated at different states of the four switches. The proposed design gives more resonant frequency bands with reasonable frequency bandwidths which can be manipulated for different applications. Moreover the stacked configuration enhances both directivity and radiation efficiency of the antenna in the desired frequency bands.

The positions and dimensions of the substrates, parasitic elements, slots and switches of the proposed antenna are optimally chosen to give as many resonant frequencies with wide bandwidths as possible depending on the applications use the same antenna.

\section{REFERENCES}

1. K. Wong, Compact and Broadband Microstrip Antenna, A Wiley-Inter Science Publication Jone Wiley \& Sons, Inc., 2002.

2. T. Gandara, R. Urban, L. Fregoli, C. Peixeiro, "Planar inverted-F antennas integrated into small multi-standard handsets," Automatika, Portugal, ATKAAF, Vol. 48, No. 1-2, pp. 45-52, 2007.

3. E. E. Khaled, A. A. Saad, "Multi-wideband compact microstrip patch antenna based on slot matching", Progress In Electromagnetics Research C, Vol. 4, pp. 169-177, 2008.

4. R. B. Waterhouse, "Design of probe-fed stacked patches," IEEE Trans. Antennas Propagat. Vol. 47, pp. 1780-1784, 1999.

5. R. Q. Lee and K. F. Lee, "Experimental Study of Two-layer Electromagnetically Coupled Rectangular Patch Antenna," IEEE Trans. Antenna Propagat., Vol. 38, pp.1298-1302, 1990. 
6. R. B. Waterhouse, J. T. Rowley, and K. H Joyner, "Stacked shorted patch antenna," Electron. Lett., Vol. 34, No. 7, pp. 612-614, 1998.

7. R. B. Waterhouse, "Broadband stacked shorted patch," Electron. Lett., Vol. 35, No. 2, pp. 98-100, 1999.

8. J. Ollikainen, M. Fischer and P. Vainikainen, "Thin dual-resonant stacked shorted patch antenna for mobile communications," Electron. Lett., Vol. 35, 1999.

9. H. Amari, "Penta band antenna based on slot matching," Project at Laird Technologies, KTH, France, March 2007.

10. M. A. Alayesh, "Analysis and design of reconfigurable multi-band stacked microstrip patch antennas (MSAs) for wireless applications," M.Sc. Thesis at University of New Mexico, Albuquerque, December, 2007.

11. IE3D Software, Version 12.30, developed by Zeland Software, Inc, 2007.

$$
\begin{aligned}
& \text { هوائي الرقعة ذو المدى الترددي الواسع والمتعدد والمحتوى } \\
& \text { على طبقات من عناصر رنين طقيلية ومجارات بموصلات } \\
& \text { السيد عصام محمد خالد1، أيمن عايد² }
\end{aligned}
$$

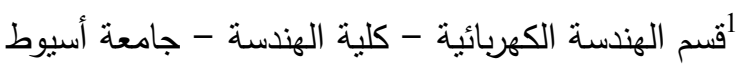

$$
\begin{aligned}
& \text { 2محطة أذاعة القصير - البحر الأحمر }
\end{aligned}
$$

تم تصميم هوائي رقعة يعتمد على فكرة موائمة المجارات. والهوائي يحتوى على طبقتن من القواعد العازلة علي كل منها رقعة محفور بها عناصر رنين طفيلية ومجارات ذات مفاتيح نوصيل وذلك فئك

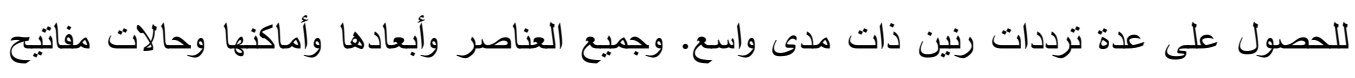
التوصيل تم تصميمها على أساس الحصول على أعلى عدد من ترددات الرنين التواسعة داسعة المدى الترددي والتى يكون عندها معدل الفقد الأنعكاسي يقل عن 2 ديسييل في المدى الترددي من 2 الى 5

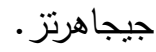

ومن النتائج تبين أن التصميم المقترح أعطي معدل نوجيه وكفائة للهوائي في المدي الذي يعمل به أفضل

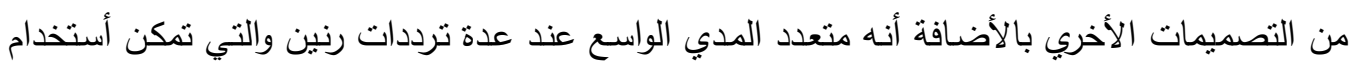
نفس الهوائي في عدة تطبيقات مختلفة 